\author{
Nazım Kunduracı ${ }^{1}$, Gülfem Binal ${ }^{2}$, İrem Nur Gamze Şimşek ${ }^{3}$ \\ ${ }^{1,3}$ Bülent Ecevit Üniversitesi Metalurji ve Malzeme Mühendisliği Bölümü, Zonguldak. \\ ${ }^{2}$ Bartın Üniversitesi Metalurji ve Malzeme Mühendisliği Bölümü, Bartın. \\ e-posta:nkunduraci@beun.edu.tr
}

Geliş Tarihi: 16.05.2016 ; Kabul Tarihi: 21.02.2017

Özet

Seramik sağlık gereçleri sektöründe üretilen ürünler için iki farklı çamur kullanılmaktadır. Bu çamurlar; vitrifiye çamurları ve fine fire clay (FFC) çamurlarıdır. Uzun ebatlı ve düşük pişme deformasyonun gerekliliği bulunan lavabo türü ürünler FFC çamurları ile üretilmektedir. FFC ürünlerine yüksek mukavemet ve düşük deformasyon davranışını reçete içerisindeki şamot hammaddesinin sağladığı

Anahtar kelimeler

Şamot;

Yerli Üretim;

Maliyet Avantajı ve

Rekabet Gücü bilinmektedir. Şamot malzemesinin sağladığı bu önemli özelliklerin yanı sıra, üretici firmaların azlığı ve yurt dışından ithal ediliyor olması yüksek maliyet ve ekonomik istikrarsızlıkları beraberinde getirmektedir. Özellikle son iki yıl içerisinde artan döviz kuruna bağlı olarak, şamot maliyetleri \%30 oranlarında artış göstermiştir. Bu durum, Türkiye'deki üretim maliyetlerinde artışa sebep olarak seramik sağlık gereçleri üreticileri açısından rekabet güçlüğü oluşturmuştur. Bu çalışmada, seramik sağlık gereçleri sektöründe Türkiye'deki firmaların rekabet gücünün arttırılması ve dünyada büyük bir pazar açı̆̆ı olan şamot sektörüne yerli alternatiflerin sunulması amaçlanmıştır. İthal şamot hammaddesine alternatif olarak kullanılabilecek hammaddeler ve yerli sentez şamot hammaddeleri bu çalışmada ithal şamot yerine kullanılmıştır. Deneme sonuçlarına göre, ithal şamotun yerine farklı türevlerin üretilebileceği ve maliyet açısından da önemli avantajlar sağlanabileceği görülmüştür.

\title{
Research and Synthesis of Alternative Domestic Fireclay Materials in Sanitaryware Fine Fire Clay Products
}

Abstract

Two different slips are used in the ceramic sanitary ware sector for different products. These slips are vitrified clay and fine fire clay (FFC). Large-sized products having low firing deformation requirement, like sink, are produced from FFC slips. It is known that high strength and low deformation behavior of

Keywords

Fireclay;

Domestic Production:

Cost Advantage and Competitiveness FFC products are provided by fireclay raw material. In addition to these important features of fireclay material, it is imported from quiet limited foreign manufacturers. This situation leads to high cost and economical instabilities. Especially in the last two years, fireclay costs has increased in the rate of $30 \%$ due to upgrade exchange rate. This case caused competitive challenges among the ceramic sanitaryware manufacturers in Turkey due to increased production costs. The aim of this study is to increase the competitiveness of ceramic sanitaryware companies in Turkey and offer domestic alternatives to world fireclay market. In this study, domestic synthesis of fireclay and other derivative raw materials have been used as an alternative for imported fireclay. According to the experimental results, it was observed that different materials can be produced instead of imported fireclay. Significant advantages in terms of costs can be provided by these materials. 


\section{Giriş}

Seramik sağlık gereçleri ürünlerinde büyük ebatlı ürünler, FFC (Fine Fire Clay) olarak bilinen pişmiş kil içeriği yüksek çamurlar ile dökülmektedir. Gelişen teknoloji ile birlikte şekillendirme proseslerinde, basınçlı döküm sistemleri de hızla yaygınlaşmaktadır. Devlet Planlama Teşkilatı'nın yayınladığı Seramik Sağlık Gereçleri Kalkınma Planı'na göre (2007-2013); basınçlı şekillendirme sistemlerinin artışına bağlı olarak, kullanılan FFC çamurlarının üretiminde artış gözlenmiştir.

FFC üretiminde kullanılan ana hammaddeler kil, kaolen, kuvars ve şamottur. Reçete incelendiğinde, şamot haricinde tüm hammaddelerin alternatiflerinin piyasada bulunduğu görülmektedir. Özellikle kaolen zenginleştirme ve öğütme işlemlerinin yüksek yatırım maliyetleri sebebiyle, şamot malzemesi Türkiye'deki bütün FFC üreten seramik firmaları tarafından ithal edilmektedir. Türkiye'deki seramik sağlık gereçleri üreticileri $\mathrm{FFC}$ ürün üretiminde reçetelerinde ortalama \%30 oranında şamot malzemesi kullanmaktadır. FFC bünyelere kattığı özellikler açısından incelenecek olursa; şamot malzemesi, pişmiş bir hammadde olduğu için yarı mamul ve pişmiş mamul halindeki ürüne mukavemet sağlamakta ve deformasyon davranışını minimize etmektedir. Şamot malzemesinin nihai ürün özelliklerine etkileri göz önünde bulundurulduğunda, FFC bünyelerde bu malzemenin kullanımının büyük önem taşıdığı görülmektedir. FFC seramik sağlık gereçlerindeki bu dışa bağımlılık, nakliyeden kaynaklı maliyet ve karbon ayakizi miktarının artışına sebep olmaktadır. Ayrıca döviz kurlarındaki dalgalanmalar da, zaman zaman beklenmedik maliyet artışlarına yol açarak küçük ölçekli firmalarda büyük zararlar bırakabilmektedir. Son iki yıl içerisinde artan döviz kuruna bağı ılarak da ithal hammadde fiyatları da üretim maliyetleri artışına sebebiyet vermektedir. Bu bağlamda seramik sağlık gereçleri sektöründe rekabeti sağlamak amacıyla yurt dışından ithal edilen hammaddelerin yüzdesinde azalma olması gerekliliği öngörülmektedir. Ayrıca, ithal hammaddelerin yol açtığı lojistik maliyetleri de göz önüne alınacak olunursa, rekabet gücünü azalttığı görülmektedir. Seramik sağlık gereçlerinde kullanılan şamot alternatifi malzemelerin neler olabileceğinin araştırılmasına başlamadan önce, şamot malzemesinin XRD analizi ile fazlarının detaylı olarak ortaya konulmasının faydalı olacağı düşünülmüştür. 2014 yılında Kunduracı ve arkadaşlarının FFC lavaboların inceltilmesi için yaptıkları çalışmada, FFC reçetesinden \%30 oranındaki şamot malzemesi çıkartılarak \%5 oranında sentetik müllit tozu kullanılmıştır. Sentetik müllit tozunun şamot yerine kullanılmasıyla yarı mamul mukavemetlerinde ve pişme mukavemetlerinde artış sağlanmış ve buna bağlı olarak FFC lavaboların kalınlıkları \%25 oranında azaltılabileceği görülmüştür. Yine aynı çalışmada, şamot malzemesinin mineralojik içeriği incelenmiş ve yaklaşık olarak $\% 50$ müllit, $\% 5$ kristobalit, $\% 5$ korundum, \%40 amorf faz bulunduğu görülmüştür. 1990 yılında Michel ve arkadaşlarının alümina-silika sistemlerini inceledikleri çalışmalarında, müllit fazının seramik bünyelerde mukavemet sağladığı belirtilmiştir. 1993 yılında Schneider'in seramik müllitler üzerine yaptığı yayında; müllitin, düşük ısıl genleşme, yüksek ergime noktası, iyi sürünme dayanımı, düşük ısıl iletkenlik ve kimyasal kararlılık gibi özellikleri ile son yıllarda yüksek sıcaklık uygulamalarında kullanılabilen malzemeler arasına girdiğini belirtmiştir. Yine aynı çalışmada müllitin; kaolen tipi minerallerin ısıtılması ile oluşabildiği gibi, alümina-silika karışımlarının reaksiyonu sonucunda da elde edilebileceği belirtilmiştir. $\mathrm{Al}_{2} \mathrm{O}_{3}-\mathrm{SiO}_{4}$ sistemi seramikte en önemli ikili sistemlerden birisi olup, bu sistemde termodinamik olarak kararlı oluşan tek ara bileşiğin müllit olduğu ifade edilmiştir. Bu veriler ışığında, seramik sağlık gereçleri sektöründe kullanılan şamot malzemesinin yerine alternatif malzemelerin araştırılması noktasında kullanılacak alternatif malzemelerin içerisinde müllit fazının arttırılması gerektiği veya müllit fazının benzer özelliklerini taşıyan yeni fazların oluşturulması gerektiği belirlenmiştir. 2007 yılında Kong ve arkadaşlarının alümina silika karışımından yüksek enerjili öğütme sistemlerini kullanarak 1200 ㄷ gibi düşük 
sıcaklıklarda kararlı müllit fazı elde ettikleri çalışma incelendiğinde, öğütme etkisi ve safsızıkların etkisi ile 1200 드 gibi düşük sıcaklılıklarda kararlı müllit fazının elde edilebileceği bildirilmiştir. Normal koşullarda bu tip müllit fazının elde edilmesi, 1500 oC üzerindeki sıcaklıklarda gerçekleşmektedir.

$\mathrm{Bu}$ çalışmanın amacı, FFC seramik sağlık gereçlerinde göreceli olarak yüksek miktarlarda kullanılan ithal şamot malzemesine alternatif yerli hammadde sentezlenmesi ile seramik sağlık gereçleri üretim maliyetlerini azaltarak, rekabet gücünün arttırılmasıdır. Sentezleme metodunu etkileyen değişkenlerin optimizasyonuyla FFC seramik sağlık gereçlerinde hem üretim maliyetinin düşürülmesi, hem de bu konuda dışa bağımlılığın azaltılması hedeflenmiştir.

\section{Materyal ve Metot}

Bu çalışmada müllit içeriği yüksek olan Symlox tozu (ticari müllit) ve alümina-silika-tungsten karbür karışımından elde edilen toz karışımı 300 rpm'de 2 saat süreyle bilyalı değirmende öğütüldükten sonra ısıl işlem uygulanarak şamot malzemesi sentezlenmiştir. Sentezlenen şamot malzemesi, ithal şamot yerine kullanılarak yeni FFC reçeteleri hazırlanmıştır. Deneme sonuçları referans reçetenin $\mathrm{XRD}$ analizleri $\mathrm{Cu}-\mathrm{K} \alpha$ monokromatik X ışınlarıyla, $40 \mathrm{kV}$ voltaj ve $30 \mathrm{~mA}$ referans reçete ile karşılaştırmalı olarak incelenmiştir. Oluşturulan iki yeni reçete ve SEM incelemeleri ikincil elektron tekniği kullanılarak yapılmıştır (ZEISS EVO, Almanya). Yarı mamül ve pişmiş mamul mukavemetleri için hazırlanan çamur döküm yöntemiyle şekillendirilip $120-160{ }^{\circ} \mathrm{C}$ arasında kurutulduktan sonra $1220{ }^{\circ} \mathrm{C}$ 'de pişirilmiştir. Pişirilen numuneler uygun ebatlarda kesilip; yarı mamül mukavemeti endüstride kullanılan yöntemlerle, pişmiş mamül mukavemeti TS EN ISO 10545 standardına uygun şekilde ölçülmüştür. Yine tüm reçetelerin, su emme, deformasyon ve küçülme değerleri endüstriyel yöntemlerle ölçülmüştür. Şamot kullanılarak hazırlanan standart reçete STD, sentetik müllit tozu kullanılarak hazırlanan reçete $\mathrm{DN}-1$ ve alüminasilika-tungsten karbür tozu kullanılarak hazırlanan reçete ise DN-2 olarak isimlendirilmiştir. Çizelge 1 'de hazırlanan reçetelerde kullanılan hammaddelerin kimyasal analiz sonuçları yer almaktadır. Çizelge 2 'de ise standart reçete ve deneme reçetelerinin rasyonel analizlerine yer verilmiştir. Rasyonel analizler Seramik Araştırma Merkezi tarafından, XRF yöntemiyle yapılmıştır.

Çizelge 1. Hammaddelerin kimyasal kompozisyonlar (\%kütle)

\begin{tabular}{|c|c|c|c|c|c|c|c|c|c|c|c|}
\hline & $\begin{array}{c}\text { Kızdırma } \\
\text { Kaybı }\end{array}$ & $\mathrm{SiO}_{2}$ & $\mathrm{Al}_{2} \mathrm{O}_{3}$ & $\mathrm{Fe}_{2} \mathrm{O}_{3}$ & $\mathrm{TiO}_{2}$ & $\mathrm{CaO}$ & MgO & $\mathrm{Na}_{2} \mathrm{O}$ & $\mathrm{K}_{2} \mathrm{O}$ & $\mathrm{SO}_{3}$ & $\mathrm{WO}_{3}$ \\
\hline Albit & 0,15 & 70,36 & 18,30 & 0,08 & 0,19 & 0,53 & 0,04 & 10.17 & 0,25 & - & - \\
\hline Kuvars & 0,20 & 98,75 & 0,20 & 0,10 & 0,30 & 0,04 & 0,02 & 0,10 & 0,55 & 0,01 & - \\
\hline Kil 1 & 0,10 & 58,11 & 37,80 & 1,57 & 0,28 & 0,22 & 0,42 & 0,12 & 1,39 & 0,06 & - \\
\hline Kil 2 & 10,30 & 56,40 & 29,59 & 1,85 & 1,13 & 0,26 & 0,48 & 0,21 & 1,59 & - & - \\
\hline Kaolen 1 & 12,41 & 48,72 & 36,46 & 0,77 & 0,47 & 0,14 & 0,17 & 0,19 & 0,79 & 0,01 & - \\
\hline Kaolen 2 & 11,40 & 48.02 & 36,01 & 1,02 & 0,06 & 0,07 & 0,40 & 0,13 & 2,73 & - & - \\
\hline İthal Şamot & 0,02 & 59,94 & 39,14 & 1,80 & 0,50 & & & 0,16 & 1,15 & & - \\
\hline $\begin{array}{c}\text { Sentetik } \\
\text { Müllit }\end{array}$ & 0,01 & 32,00 & 67.99 & - & - & - & - & - & - & - & - \\
\hline $\begin{array}{c}\text { Yerli Üretim } \\
\text { Şamot }\end{array}$ & 0,02 & 27,00 & 70,98 & - & - & - & - & - & - & - & 2,00 \\
\hline
\end{tabular}


Çizelge. Hammaddelerin Rasyonel Analizleri (\%kütle)

\begin{tabular}{ccccc}
\hline & K-feldspat & Na-feldspat & Kaolen & Kuvars \\
\hline STD & 6,39 & 3,65 & 63,47 & 26,49 \\
\hline DN-1 & 6,21 & 4,83 & 62,47 & 26,49 \\
\hline DN-2 & 6,21 & 4,76 & 62,78 & 26,26 \\
\hline
\end{tabular}

\section{Bulgular ve Tartışma}

Denemelerde kullanılan ithal şamot malzemesinin ve ithal şamot alternatifi olarak kullanılan malzemelerin SEM görüntülerine Şekil 1'de yer verilmiştir. Buna göre, Itthal şamot malzemesi plaka düzlemleri şeklindeyken, sentetik müllit tozu visker şeklinde ve yerli sentez şamot ise granül şeklinde kristal yapılara sahip olduğu görülmüştür.
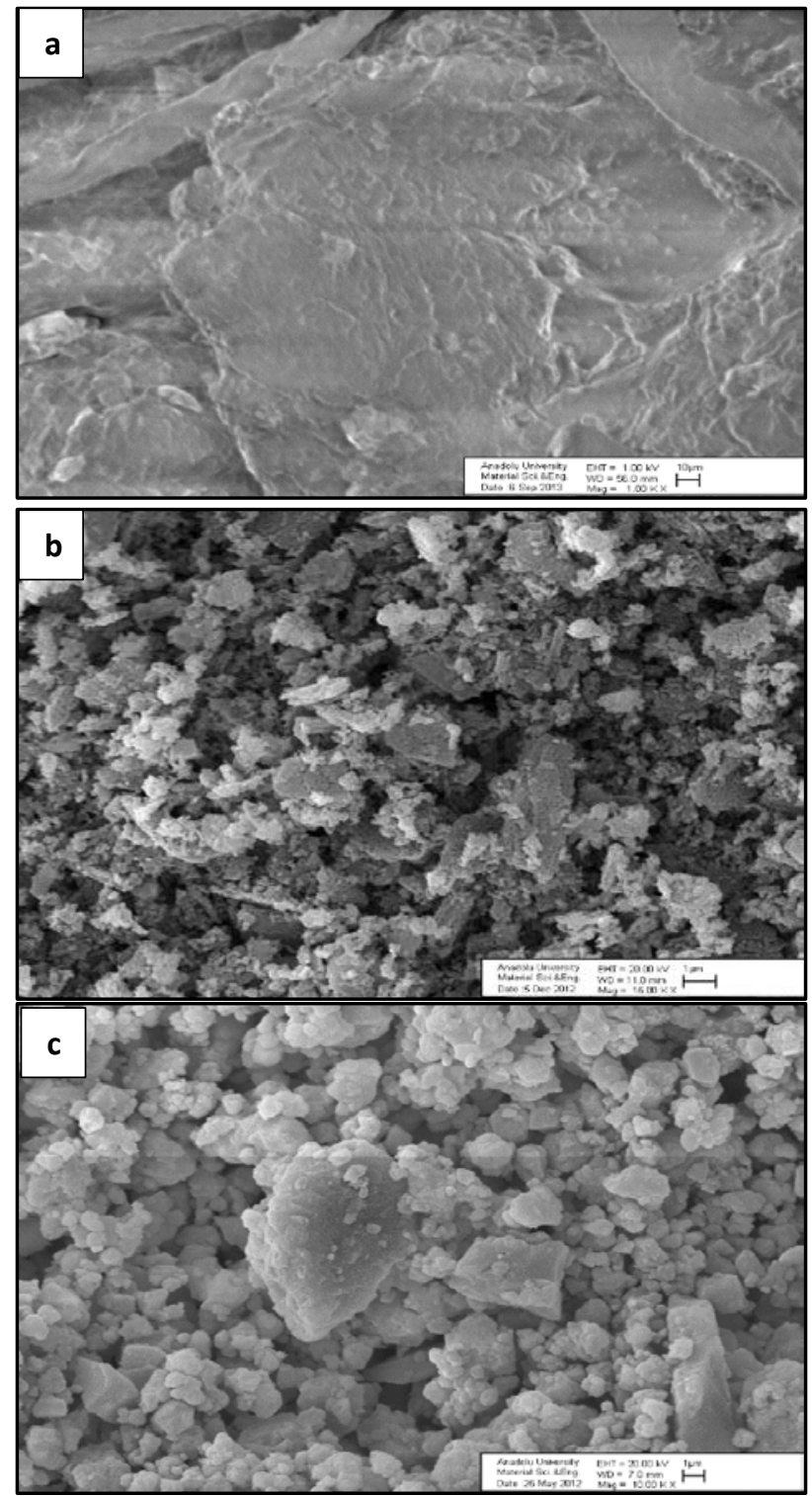

Şekil 1. İthal şamot malzemesinin ve şamot alternatifi malzemelerin SEM görüntüleri. (a) ithal şamot, (b) ticari müllit, (c) yerli sentez şamot.
Şekil 2'de, referans hammaddenin ve alternatif hammaddelerin XRD paternleri verilmiştir. Bu XRD paternleri incelendiğinde, bütün reçetelerde müllit pikinin bulunduğu söylenebilmektedir. DN-2 reçetesinde kullanılan yerli üretim şamot malzemesinin, XRD pikleri arasında müllitin yanı sıra korundum, kristobalit ve wolfram oksit bulunmaktadır. Müllit faz miktarları ithal şamot malzemesine göre düşük görünmektedir.
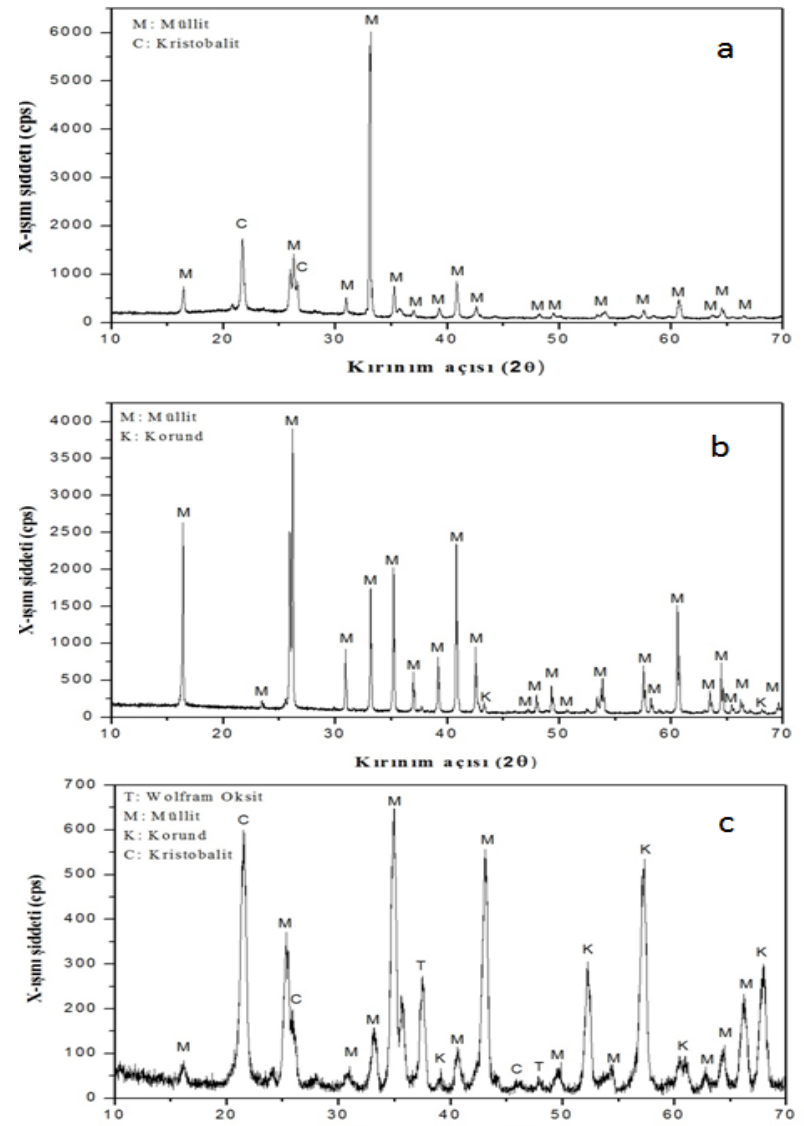

Şekil 2. İthal şamotun ve şamot alternatifi kullanılan malzemelerin XRD paternleri. (a) ithal şamot, (b) sentetik müllit, (c) yerli sentez şamot

Tablo 3'te, STD reçete ve deneme reçeteleri DN-1 ve DN-2'nin başlıca fiziksel değerleri ile yarı mamul ve pişmiş mamul mukavemetleri gösterilmektedir. Oluşturulan iki reçete denemesinde de, reolojik özellikler açısından standart reçete değerlerinin elde edildiği görülmüştür. En yüksek mukavemet değerlerinin DN-1 reçetesinde elde edildiği, DN-2 reçetesinin mukavemet değerlerinin ise STD reçeteden yüksek olduğu belirlenmiştir. 
Tablo 3. Deneme çamurların özelliklerinin referans çamur ile karşılaştırılması

\begin{tabular}{|c|c|c|c|}
\hline & STD & DN-1 & DN-2 \\
\hline L. Ağırlığı & 1875 & 1875 & 1875 \\
\hline Brookfield (cp) & 655 & 645 & 635 \\
\hline Kuru Kü̈cülme (\%) & 2 & 2,8 & 3,2 \\
\hline Pişme Küçülme (\%) & 3,8 & 6,7 & 5,7 \\
\hline Toplam Küçülme (\%) & 5,8 & 9,5 & 8,9 \\
\hline Deformasyon (mm) & $8-9$ & $10-10$ & $10-11$ \\
\hline Su Emme (\%) & 9,5 & 6,21 & 8,86 \\
\hline Kuru Mukavemet $\left(\mathrm{kg} \backslash \mathrm{cm}^{2}\right.$ ) & 26,93 & 31,73 & 30,19 \\
\hline Pişmiş Mukavemet $\left(\mathrm{kg} \backslash \mathrm{cm}^{2}\right)$ & 378,74 & 467,93 & 438,72 \\
\hline Maliyet (TL/ton) & 410 & 384 & 350 \\
\hline
\end{tabular}

Maliyet-mukavemet ilişkisi incelendiğinde, reçetelerin fiyat-performans değeri hakkında yorum yapmak mümkündür. Buna göre, şamot yerine kullanılması önerilen hammaddelerin kullanımıyla, daha düşük maliyetlerde daha yüksek mukavemet elde edilebilmektedir.

Elde edilen sonuçlara göre, seramik sağlık gereçleri FFC çamurlarında \% 30 civarlarında kullanılan şamot malzemesinin tamamen reçeteden çıkartılarak yerine $\% 5$ oranında sentetik müllit kullanımının veya sentez yerli şamot kullanımının mukavemet ve maliyet açısından FFC bünyeleri daha avantajı hale getirdiği görülmüştür. Buradaki tek darboğaz, DN-1 ve DN-2 reçetelerinin STD reçeteye göre farklı pişme küçülmelerine sahip olmalarıdır. Bu durumun, üretimde kullanılan kalıp boyutlarının değiştirilmesiyle giderilebileceği düşünülmektedir. Ayrıca DN-1 ve DN-2 reçeteleri, sağladıkları düşük su emme değerleri ile ürün kullanım ömürlerinde artış sağlayabilecektir.

DN-1 reçetesinde; şamot malzemesinden daha fazla müllit fazı içeren sentetik müllit, çok düşük oranlarda kullanılmasına karşın yapı içerisinde bulunan iğnemsi kristalleri sayesinde daha yüksek mukavemet değerleri sağlamaktadır. DN-2 reçetesinde kullanılan yerli üretim şamot malzemesinin, XRD pikleri arasında müllitin yanı sıra korundum, kristobalit ve wolfram oksit bulunmaktadır. Müllit faz miktarları ithal şamot malzemesine göre düşük görünmektedir. Bu durumda yapı içerisine ilave edilen yerli malzemenin ve STD reçetenin mukavemet değerlerinin düşük olması gerekmektedir. Ancak deneme sonuçlarında, DN-2 reçetesinin yarı mamul ve pişmiş mamul mukavemetleri STD reçetesinden yüksek bulunmuştur. Karşılaşılan bu durum, Kong ve ark. (2004)'ın yaptığı çalışmayla açıklanabilmektedir. Bu çalışmaya göre, alüminasilika-tungsten karbür sisteminde $900 \stackrel{\circ}{ } \mathrm{C}$ sıcaklığın üzerine çıkıldığında tungsten karbürün bozunarak tungsten okside dönüştüğü ve uzun çubuksu yapılar oluşturduğu ve bu uzun çubuksu yapılar üzerine, silikaca zengin camsı fazın alümina tanelerini çözerek visker şeklinde büyümeye yol açtığı belirtilmektedir. DN-2 reçetesinin mukavemet değerlerinin yüksek oluşu, bu mekanizmanın ve tungstenin sahip olduğu yüksek mukavemetin etkisiyle açıklanabilmektedir.

\section{Sonuçlar ve Değerlendirme}

$\mathrm{Bu}$ çalışmada; ithal şamot malzemesinin yerine piyasada ticari olarak satılan müllit malzemesinin kullanılabildiği gösterilmiştir. Ayrıca alümina-silikatungsten karışımından hazırlanarak sentezlenen malzemenin de ithal şamot yerine kullanılabileceği görülmüş olup ekonomik olarak en çok katkıyı bu sentez malzemenin sağladığı tespit edilmiştir. Çalışma kapsamında sunulan iki farklı şamot muadili hammadde ile düşük maliyetli ve yüksek mukavemetli ürünler üretilebilecek ve böylelikle Türkiye'deki seramik sağlık gereçleri sektörünün küresel rekabet gücü arttırılabilecektir.

\section{Kaynaklar}

Michel, D., Mazerolles, L. and Portier, R., 1990. Directional solidification in the alumina-silica system: microstructure and interfaces. Ceramic Transactions, 6, 435-437.

Seramik Sağlık Gereçleri Sektörü Dokuzuncu Kalkınma Planı, 2007-2013. Devlet Planlama Teşkilatı Müsteşarlığı.

Schneider, H. Schmücker, M., İkeda K. and Kaysser, W.A., 1993. Optically translucent mullite ceramics. Journal of American Ceramic Society, 76, 2912-2914. 
Kunduracl, N., ve Aydın, A., 2015. FFC Seramik Sağlık Gereçlerinin Yarı Mamül ve Pişmiş Mamul Mukavemetlerini Arttırarak Ultra Ince FFC Lavaboların Üretimi. International Journal of Engineering Research and Development, 7, (2) 1-4.

Kong, L. B., Zhang, T.S., Ma, J. and Boey, F. Y. C., 2007. Anizotropic Grain Growth in Mullite Powders as a Result of High Energy Ball Milling. Journal of American Ceramic Society, 90 (12) 4055-4058. 